\title{
Peri-Uterine Focal Abscess in Bitch (Shih Tzu), its Clinical Investigation and Management: Rare Case Study
}

\author{
Hamid Shah ${ }^{1}$, Jameel Gazi ${ }^{2}$, Burhan Nabi $^{3}$ and Munazah Shahzad ${ }^{4}$ \\ ${ }^{1}$ VETLAB-All Vet Diagnostic Solutions, New Delhi-110016, India \\ ${ }^{2}$ Veterinary Surgeon, Millennium Pet Hospital, New Delhi, India \\ ${ }^{3}$ Division of Veterinary Medicine, Faculty of Veterinary Sciences \\ and Animal Husbandry, SKUAST-J, India \\ ${ }^{4}$ Division of Veterinary Parasitology, Indian Veterinary Research Institute (IVRI), \\ Izatnagar, Bareilly, Uttar Pradesh, India \\ *Corresponding author
}

\section{A B S T R A C T}

\section{Keywords}

Abscess,

Anamnesis,

metabolic,

ovariohysterectomy, peri-uterine

Article Info

Accepted:

18 May 2020

Available Online:

10 June 2020
Peri-uterine abscess is uncommon finding in small animals leading to various uterine ailments and thus metabolic derangements, our study is one such finding in Shih Tzu bitch having age 9 months with anamnesis of vomiting, anorexia and diarrhoea. Upon clinical examination and ultrasonography evaluation the animal was said to be having uterine abscess with some changes in the serum biochemical constituents. The spontaneous removal of uterine abscess may not be the effective treatment for such conditions so ovario hysterectomy is the only ministration for the safeguard of animal life with proper post-operative care.

\section{Introduction}

Pelvic abscess formation is unusual snag, accounting for today's widespread use of antibiotics. Peri-Uterine abscesses or parametritic abscesses are mostly seen in cattle on the dorsal portion of the uterine body or in the dorsal part of one uterine horn, measuring upto $30 \mathrm{~cm}$ in diameter and frequently reported in cattle than in other species which might due to uterine manipulation involving the use of instruments in those animals. The peri-uterine abscess or para-metritic abscess is the result of inflammation in the connective tissue surrounding the uterus which is caused by the incursion of septic material from an injured place in the mucous membrane of the female 
genital tract. The suppurating parametritis, whether tied with the puerperium or not, may result in the development of abscesses not only at the point of invasion, but also in more secluded parts, probably from suppurating lymph glands. The sequel of pelvic abscess in the later stage may be perforation into rectum or bladder or into some other part of genital tract usually into vagina and thereby causing the excretion of purulent discharges as mentioned by Fenger, C. (1885).

The uterine abscess has not been reported in the small animals like dog and the cause for its formation may be numerous. The perianal and genital areas are the principal reservoirs of the E.coli organism known to cause UTI in dogs as reported by Janke et al., (1989) and the ascending transport of E.coli bacteria from vagina into the reproductive tract after voiding of urine can lead to the formation of uterine abscesses as mentioned by Khaliq et al., (2019) while re-counting the common cause of uterine abscess in humans, which can be said as the possible cause for the formation of uterine abscess even in the canines, other possible cause for the formation of uterine abscess in canines is due to the formation of previous haematocele of uterus with subsequent infection due to pelvic cellulitis etc.

The most effective way to determine the size and location of an abscess is by use of different imaging techniques. Pelvic ultrasound is the first method of choice to evaluate a pelvic mass followed by transvaginal ultrasound which is superior over former. Pelvic ultrasonography can help in differentiating between the fluid-filled lesion and solid lesion. It is a quite easy and inexpensive method of imaging with no ionizing radiation. The common finding of ultrasound examination for an abscess appears a collection of pus with different sizes of delicate internal echoes.
The removal of the abscess, whether spontaneous or artificial, will be followed by repudiation of the abscess wall, and cure; but there some chance that the abscess may not close, insufficient outlet or invasion of new septic material from the perforation opening causes the abscess to continue and that if not overcome by surgical treatment, the patient's life will slowly but surely be destroyed either by causing chronic septicaemia or by amyloid degeneration of various organs.

\section{Materials and Methods}

A 9 months old Shih Tzu bitch was presented with the history of anorexia, vomiting and diahorrea. The abdomen was distended apparently. Upon physical examination the rectal temperature was $104^{\circ} \mathrm{C}$, thereafter proper restraining of animal was ascertained and blood was collected from cephalic vein aseptically for haemato-biochemical evaluation using Hematology-Autoanalyser (Nihon-Koden) and Biochemistry analyserCoralyzer-200. Ultrasonographic evaluation was done using microconvex probe $-5 \mathrm{MHz}$ and thereafter ovariohystrectomy (OHE) was performed under xylazine and ketamine anaesthetic combination and maintained under diazepam and ketamine followed by appropriate post-operative care with antibiotic and analgesic for diminution of pain.

\section{Results and Discussion}

Haematological examination showed $\mathrm{Hb}$ level $13.80 \mathrm{~g} / \mathrm{dl}$ with differential count of Neutrophils 74\%, Lymphocyte $20 \%$ and Monocytes and Eosinophills 3\% respectively, a leucocyte within the normal reference range could perhaps reveal a shift from leucocytosis to leucopoenia (commonly seen in the uterine disorders) i.e. leucocytosis appearing earlier in the pathogenesis as also mentioned by Jitpean et al., (2014). 
Table.1 Biochemical investigation in Shih Tzu with Peri-Uterine Abscess

\begin{tabular}{|c|c|}
\hline Parameter & Values \\
\hline BUN (mg/dl) & 11.60 \\
\hline Creatinine (mg/dl) & 0.40 \\
\hline Total Protein (g/dl) & 5.70 \\
\hline Calcium (mg/dl) & 8.71 \\
\hline Random Blood Sugar (RBS) (mg/dl) & 83.30 \\
\hline AST (U/L) & 18.26 \\
\hline ALT (U/L) & 42.75 \\
\hline ALP (U/L) & 1258.68 \\
\hline
\end{tabular}

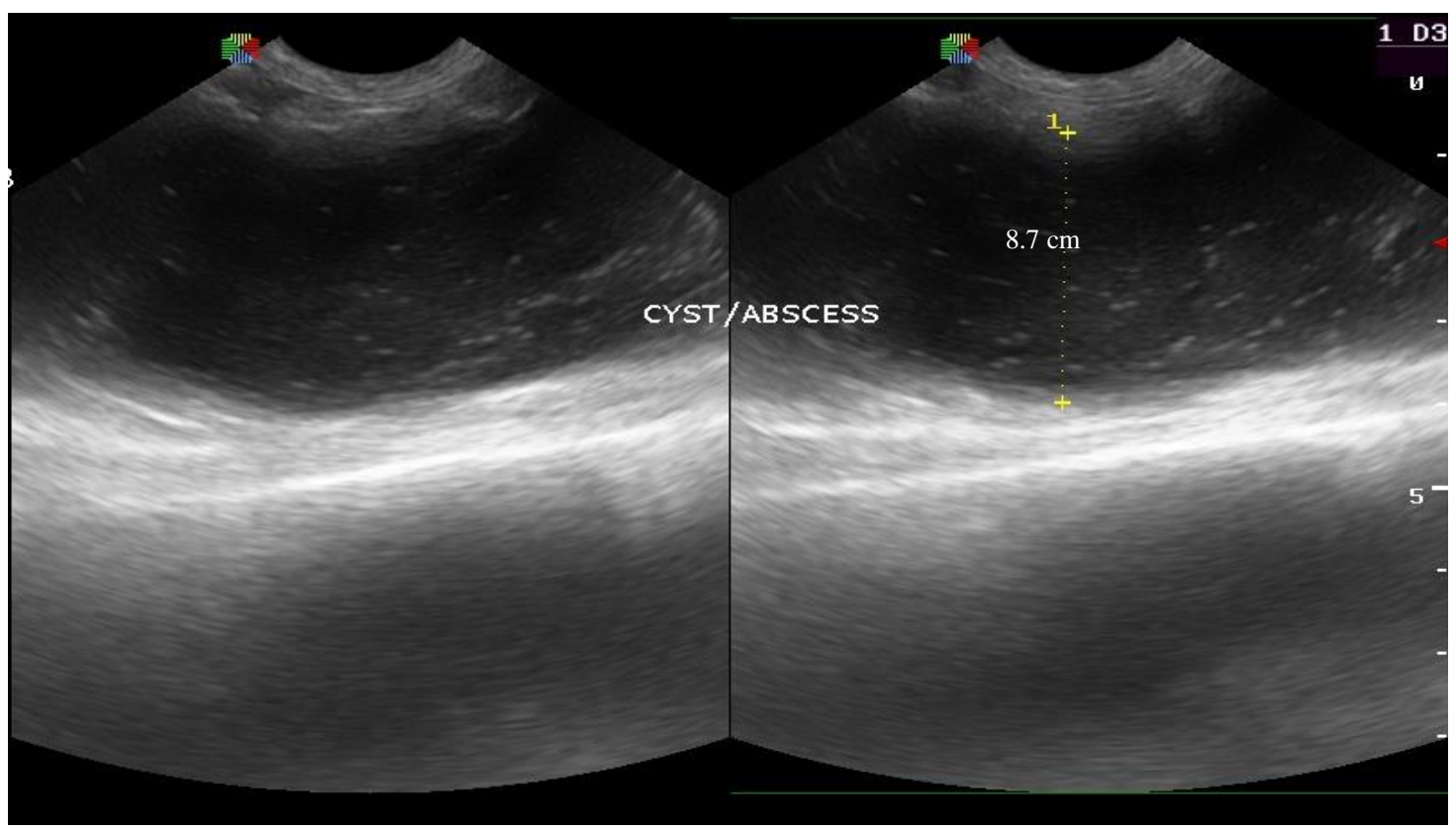

Fig.1 Ultrasonographic imaging of peri-uterine abscess
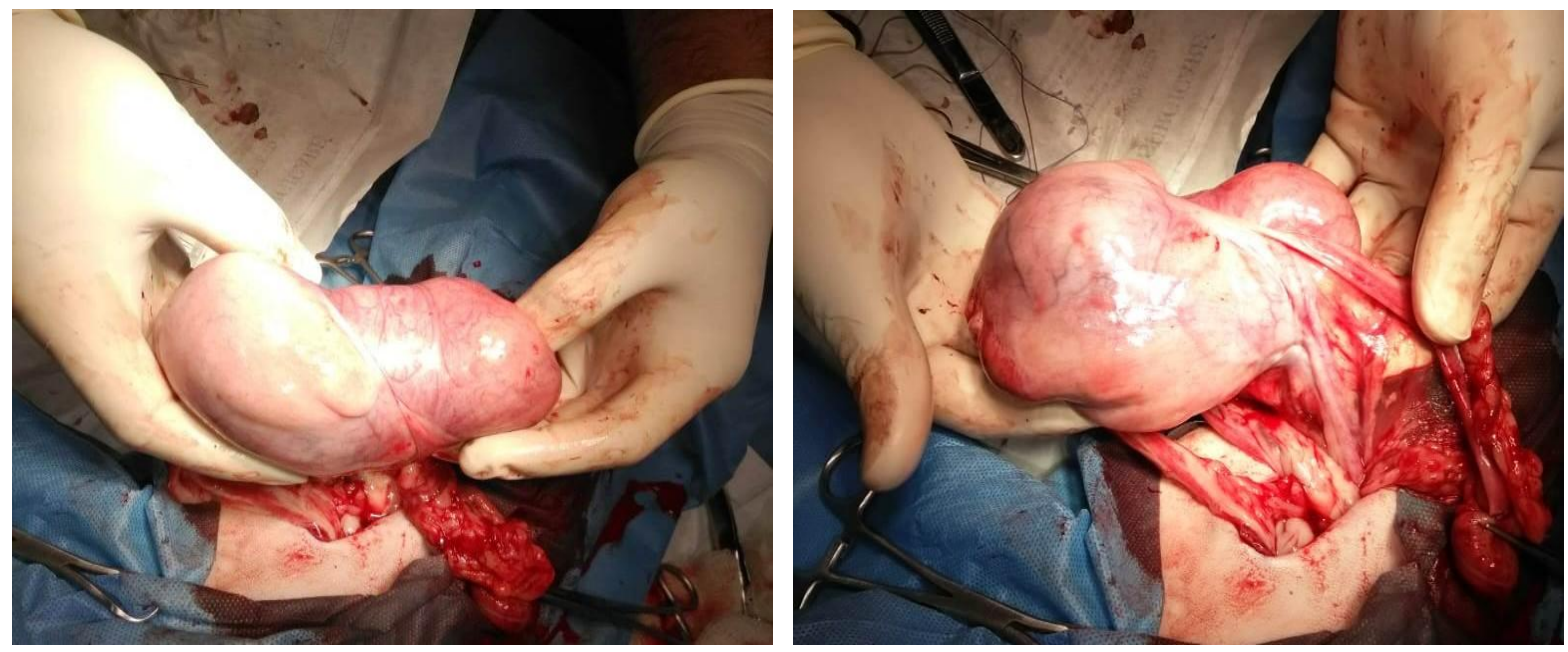

Fig.2 Gross examination of Peri-uterine abscess after OHE 
Serum biochemical examination as depicted in Table 1 revealed BUN $11.60 \mathrm{mg} / \mathrm{dl}$, Creatinine $0.40 \mathrm{mg} / \mathrm{dl}$, Total proteins 5.70 $\mathrm{g} / \mathrm{dl}$ suggestive of no renal failure usually associated with the uterine diseases, our findings are in similarity with Mustafa et al., (1999). There was mild hypocalcaemia with values as $8.71 \mathrm{mg} / \mathrm{dl}$, also reported by the Mustafa et al., (1999) in the bitches affected with pelvic inflammatory disease.

The Random blood sugar (RBS) was 83.30 $\mathrm{mg} / \mathrm{dl}$ remained unaffected as also mentioned in some of the cases by Arena et al., (2009) but need to be studied in large number of animals so as to understand the effect of uterine diseases on blood sugar level. The liver parameters as depicted in Table 1 revealed increase in AST value as $18.26 \mathrm{U} / \mathrm{L}$, normal ALT value as $42.75 \mathrm{U} / \mathrm{L}$ and increased ALP value $1258.68 \mathrm{U} / \mathrm{L}$. Our results are in affirmation with the findings of Lettow (1961), Borresen and Skrede (1980), Nelson et al., (1982), Mustafa et al., (1999) who also found the pronounced increase in the AST values, no change in the serum ALT values and increase in ALP values in the bitches suffering from uterine disorders. The increase of AST can be described either by a process of hepatocyte degeneration at higher endotoxin levels, or by breakdown of skeletal muscle, relating with an increased creatinekinase level and increased ALP can be attributed to the hepatic insufficiency also another cause of decreased BUN.

Ultrasonography examination revealed anechoic sacculation at the level of uterine horns (Fig.1) measuring about $8.7 \mathrm{~cm}$. No colour flow was noticed on the Doppler studies. The other vital abdominal organs were normal with no abnormalities. On the next day Ovariohystrectomy (OHE) was performed under xylazine and ketamine anesthetic combination and maintained under diazepam and ketamine. Following standard operating procedure, the uterus was removed along with the abscess and ovaries. After the OHE, post-operative care was taken for five days with ceftriaxone and tramadol and the bitch recovered uneventfully. The gross examination of the genital tract after OHE revealed presence of large abscess on its surface. The abscess was present on the dorsal aspect of the right uterine horn (Fig-2). The diameter of the abscess was approximately about $10 \mathrm{~cm}$ measured using scale. The abscess was capsulated and filled with thick pus like material.

\section{References}

Arena, M.N., Albino, M.V.C., Botelho, F.A., Luchi, R.A.S, Ponce, F.G., Severo, J.S., 2009. Evaluation of Blood Glucose in dogs with Pyometra. $34^{\text {th }}$ World Small Animal Veterinary Association World Congress Proceedings, Sao Paulo, Brazil.

Berresen, B. and Skrede, S., 1980. Pyometra in the $\operatorname{dog}-\mathrm{A}$ pathophysiological investigation. $\mathrm{V}$. The presence of intrahepatic cholestasis and an "acute phase reaction". Nord. Vet.-Med. 32 :378-386.

Fenger C (1885). Annals of Surgery. 1(5), 393-423.

Janke B.H., Francis D.H., Collins J.E., Libal M.C., Zeman D.H., Johnson D.D., 1989. Attaching and effacing Escherichia coli infections in calves, pigs, lambs, and dogs. J Vet Diagn Investig. 1:6-11.

Jitpean, S., Strom-Holst, B., Emanuelson, U., Hoglund, O.V., Pettersson, A., AlnerydBull, C., \& Hagman, R., 2014. Outcome of pyometra in female dogs and predictors of peritonitis and prolonged postoperative hospitalization in surgically treated cases. BMC Veterinary Research. 10:6.

Khaliq K., Nama N., Mahdy H., Waheed A., 
2019. Pelvic Abscess InStatPearls [Internet]. StatPearls Publishing.

Mustafa K., Ayhan B., Nil E., Selim A., Murat F., 1999. The Use of Laboratory Findings in the Diagnosis of $\mathrm{CEH}-$ Pyometra Complex in the Bitch. Tr. J. of Veterinary and Animal Sciences.
23:127-133.

Nelson, R.W., Feldman, E.C., Stabenfeldt, G.H., 1982. Treatment of canine pyometra and endometritis with prostaglandin $F_{2 \alpha}$. J.A.V.M.A. 181:899903.

\section{How to cite this article:}

Hamid Shah, Jameel Gazi, Burhan Nabi and Munazah Shahzad. 2020. Peri-Uterine Focal Abscess in Bitch (Shih Tzu), its Clinical Investigation and Management: Rare Case Study. Int.J.Curr.Microbiol.App.Sci. 9(06): 2087-2091. doi: https://doi.org/10.20546/ijcmas.2020.906.255 